\title{
LA DESECACIÓN HISTÓRICA DE LOS HUMEDALES DEL MEDIO GUADALQUIVIR. RELACIONES ECOCULTURALES, ECONÓMICAS Y SANITARIAS
}

\author{
José Naranjo-Ramírez; Martín Torres-Márquez y Rafael F. Vega-Pozuelo \\ Departamento de Geografía y Ciencias del Territorio \\ Universidad de Córdoba
}

\section{RESUMEN}

Análisis de los procesos de desecación histórica que han sufrido algunos humedales de la zona que, en la Depresión del Guadalquivir, comprende el tramo medio de dicho río, con estudio detallado de algunos casos significativos. Contrasta esta actitud desecadora con la posterior valoración y protección de un conjunto de lagunas que ofrecen un contrapunto de gran valor ecológico en un paisaje de actividad agraria dominante. Las singularidades paisajísticas y la biodiversidad que albergan estos humedales han sido la base para la transformación de aquel paisaje agrario en un conjunto destacado y singular por su patrimonio natural. Desvelar las circunstancias y avatares acaecidos en este proceso será el objetivo de nuestro estudio. Para ello se acuñan dos términos originales de esta investigación: «lamafobia» o «elosfobia», que tratarán de concretar esta obsesión desecadora presente en estos lugares a lo largo de siglos.

Palabras clave: Humedal, Biodiversidad, Paisaje, Desecación, Espacios Naturales Protegidos, «lamafobia», «elosfobia».

\section{ABSTRACT}

Historical drying of wetlands in the middle Guadalquivir (Spain). Eco-cultural, economic and health relations

An analysis of the historical drying up process that suffered some wetlands in the depression in middle stretch of the Guadalquivir River (Spain), with detailed study of some significant cases. This attitude contrast with the current valuation and protection of a set of ponds which offer a counterpoint of great ecological value in a landscape of 
dominant agricultural activity. Landscape features and biodiversity that exist in these wetlands have been the reason for the transformation of the agrarian landscape in a in a prominent and singular set for its natural heritage. One of the objectives of our study is to reveal the circumstances and vicissitudes that occurred in this process. To do this we discovered two original terms of this research: «lamafobia» o «elosfobia», that realized the obsession with the drying up of this places for centuries.

Keywords: Wetlands, Biodiversity, Landscape, Protected Natural Areas, «lamafobia», «elosfobia».

\section{INTRODUCCIÓN}

Desde hace más de cuarenta años, sobre todo a partir de los acuerdos internacionales incluidos en el Convenio Ramsar de 1971, en vigor desde 1975, los humedales, tanto los que poseen el marchamo internacional, como aquéllos de menor consideración escalar, constituyen una expresión indiscutible del creciente interés científico, social y político por la conservación ambiental.

Lo adecuado de su protección ecológica o la adopción de políticas de manejo y conservación son, en el momento actual, aspectos que muy pocos discuten; pues su salvaguarda como humedales, en sus plurales expresiones ambientales y más o menos intervenidos por la acción humana, es un manifiesto científico, social, político y ético (Have, 2010) del valor ecológico que se les otorga en el presente, ya que han de seguir prestando, más allá de los intereses antrópicos particulares o de sus pretensiones económicas, sus transcendentales servicios al sustento de los procesos naturales abióticos y bióticos, tanto en su dimensión local como a otras escalas.

Unos servicios que no sólo han de conservar su vegetación o fauna naturales, pues también la propia supervivencia del hombre y su sociedad dependen en gran medida de esa conservación. Aunque, todo hay que decirlo, estos nuevos paradigmas del post-materialismo y la concepción del estrecho vínculo entre medioambiente y supervivencia humana no se han desarrollado en las regiones de economía avanzada hasta bien entrado el siglo xx (Inglehart, 1977 y 1990; Díez Nicolás, 2004 y otros).

Hasta prácticamente mediados del siglo $\mathrm{xx}$ las posturas materialistas y las convicciones industrializadoras y productivistas no consideraban de forma positiva, con muy contadas excepciones, los valores ambientales de los ecosistemas que, a duras penas, habían sobrevivido a siglos de presión y explotación humana. Al contrario, las estrategias de crecimiento económico, demográfico y político observaban lo ambiental y su conservación, más allá de la utilidad social o económica que de ello se podía extraer, como un condicionante, o incluso un impedimento, para alcanzar esos principios de crecimiento económico 
aparentemente «ilimitado», y que, casi siempre, terminaban confundiéndose con el propio desarrollo humano en su faceta colectiva o incluso individual.

Habrá que aguardar a las graves consecuencias de la II Guerra Mundial y otros episodios ambientalmente críticos, para que aparezcan los primeros estudios socioeconómicos que comienzan a incorporar las variables medioambientales al modelo de crecimiento tradicional. Una incorporación que, más allá de posturas utilitarias, habría de mantener una visión economicistas de las relaciones humanas y ecológicas.

Los primeros trabajos que intentaron establecer las relaciones entre crecimiento económico y medioambiente se ocuparon sobre todo de los recursos no renovables, pero haciendo hincapié, sobre todo en los años sesenta, en la preocupación que entrañaba la posibilidad de agotamiento de los recursos naturales finitos. En esta línea cabe mencionar las tesis y pautas expuestas en el libro The Limits to Growth (Meadows et al, 1972), en el que se alertaba de los riesgos que, desde el punto de vista de la estabilidad económica de los países desarrollados, podía suponer la sobreexplotación o el agotamiento de los recursos, una probabilidad que se habría de manifestar más aguda y drástica si se consideraban aspectos como el incremento de la población, las desigualdades económicas entre países o la tendencia a la globalización económica, social y ambiental.

La conjunción de tales variables configuraba un escenario que podía conducir al colapso de la economía y de la propia existencia de la especie sobre el Planeta (Castro Lejarriaga, 2009). Las palabras lapidarias del estudio susodicho no dejaban duda a la interpretación de sus resultados: si se mantienen las tendencias actuales de crecimiento de la población mundial, industrialización, contaminación ambiental, producción de alimentos y agotamiento de los recursos, este planeta alcanzará los límites de su crecimiento en el curso de los próximos cien años. El resultado más probable sería un súbito e incontrolable descenso tanto de la población como de la capacidad industrial (Meadows et al., 1972).

Esas afirmaciones, concisas y preclaras, que pasado el tiempo no parecen haber surtido los efectos esperados, eran el resultado de siglos de presencia humana en la Tierra; de repetidas revoluciones tecnológicas, económicas y demográficas, todas ellas bajo un paradigma antropocentrista, miope, optimista y cortoplacista, que atribuía al medio ambiente una consideración de recurso o materia prima socioeconómica.

Unos componentes naturales que, con la salvedad de ciertos espacios naturales protegidos («guetos ambientales» manipulados y controlados), sólo eran apreciables por los frutos y la utilidad material que la humanidad podía obtener de ellos, minimizando sus hostilidades «anecuménicas».

Una naturaleza que había que domesticar para recomponer o reinventar el nutricio «Paraíso Perdido»; que parecía «infinita», «eterna» y capaz de 
recomponerse por sí sola. Una naturaleza que durante siglos, quizás milenios, había sido calificada como parte desagregada del propio ser humano, pues la humanidad se ha convencido de que, una vez descendidos del árbol genealógico tropical donde vivían nuestros antepasados, nos hemos alejado para siempre de él, y de que hemos construido, al margen de la naturaleza, el reino independiente de la cultura (Morin, 2005).

Estos principios han sido, con muy contadas excepciones, los que habrían de justificar el escenario «distópico» recogido por The Limits to Growth en 1972, y que igualmente han servido para adoptar una postura agresiva y abusiva de la naturaleza en sus múltiples manifestaciones. Una actitud histórica de conflicto eco-cultural, recientemente trastornada por nuevas ideologías post-productivistas, que, entre otras acciones, ha dado cabida a una dilatada actividad humana contraria a la supervivencia de los humedales. Unos espacios naturales que, cuidados hoy por sus valores ecológicos, científicos, pedagógicos o recreativos, a lo largo de siglos han sido genuinos epítomes de la agresividad natural frente a la cultura, marginalidad económica, despoblamiento, sacralidad, fobia, pestilencia y enfermedad.

\section{«LAMAFOBIA/ELOSFOBIA》 O EL PRINCIPIO DE RELACIÓN NEGATIVA RESPECTO A} LOS HUMEDALES

Siguiendo los argumentos de Alain Roger (2007), los humedales, al menos desde una perspectiva histórica, anterior al ecuador del siglo xx, participarían del carácter de «paisaje horrible», hostil, inútil y agresivo; carácter que se extendía a otros enclaves de difícil humanización como las montañas, los desiertos o el propio litoral.

Así surgen vocablos como «orofobia», «eremofobia» o «talasofobia», significantes de una tradicional desconfianza a esos «paisajes tremendos», baldíos e «inhumanos» (Roger, 2007). Unos enclaves que, repletos de naturaleza y misterio, bien componían vacíos demográficos o habían de ser domesticados tan pronto como se dispusiera de los conocimientos y técnicas requeridas.

Las montañas, al menos hasta bien entrado el siglo XVIII, eran rincones definidos por las miradas recelosa de una sociedad agraria occidental que cimentaba su tradicional «orofobia» en las circunstancias objetivas que rodeaban a las altas cumbres. Su clima, la esterilidad de sus suelos o la dificultad para recorrer sus peligrosas pendientes eran variables más que razonables que justificaban ese carácter de «paisaje horrible».

A tales aspectos se sumaba la no desdeñable influencia de razones psicológicas, mitológicas o incluso religiosas. El mar, sus costas, o los desiertos no escapaban de esas miradas hostiles y negativas para la vida de los hombres. Antológica a este respecto resulta la tradicional «talasofobia» que durante siglos 
condicionó las miradas paisajísticas de la cultura europea de tradición judeocristiana con relación al mar y sus costas. Alain Corbin y Alain Roger profundizan en estas miradas terribles del mar. La salinidad de sus aguas, sus tormentas, marejadas, tsunamis y «monstruos marinos», eran la expresión preclara de la hostilidad de los ecosistemas marinos; que, por otra parte, parecían estar estrechamente relacionados con el Diluvio judeocristiano o con la memoria colectiva de un antiguo cataclismo destructor $\mathrm{y}$, al mismo tiempo, renovador (Corbin, 1993).

Pues, en virtud de lo expuesto, consideramos que los humedales, las áreas pantanosas, encharcadas y salinas, bien litorales, bien interiores, han participado también, aunque con alguna excepción, de esos procesos fóbicos aludidos y comunes hasta tiempos recientes. Y a este hecho y circunstancia histórica, con la licencia del lector, hemos convenido en designarlo como «lamafobia»o «elosfobia». Para el primero empleamos el vocablo latino «lama», que podríamos traducir al castellano actual como «charca, pantano o terreno pantanoso» ${ }^{1}$. Para el segundo acudimos al término griego é $\lambda o \varsigma$, cuya traslación al castellano equivaldría a «cenagal, ciénaga, pantano o tremedal».

Las razones que avalan, hasta bien entrado el siglo xx, esa «elosfobia»o recelo de los espacios húmedos son variopintas, aunque todas ellas convergen en el protagonismo de unas condiciones naturales definidas, primero, por la presencia, permanente o temporal, de agua. Y a este cariz le siguen claras connotaciones negativas y acepciones que nos llevan a la consideración de estos enclaves como parajes fronterizos de los espacios habitables, trampas cenagosas, reinos inhóspitos de las alimañas y contextos difícilmente roturables, bien por el exceso de agua o por la habitual salinidad, tanto en territorios litorales como en áreas endorreicas. Esta situación y la valoración histórica que ello supone, ha favorecido que la sociedad, al menos en el ámbito de la cultura agraria occidental, haya adoptado una posición de espaldas a estos espacios como zonas baldías e insalubres, favoreciendo por lo general unas relaciones negativas o destructivas, mucho más aún en el caso de humedales mediterráneos temporales o estacionales, en los que buena parte del año hídrico quedan prácticamente desprovistos de aguas superficiales (Casermeiro Martínez et al, 2002; Lagóstena Barrios, 2015).

Las muestras tempranas de esa tortuosa relación entre las pretensiones humanas y los humedales, expresión de la «elosfobia» apuntada, están perfectamente ilustradas si analizamos, por ejemplo, las acciones desecantes y la

1. El Diccionario de la RAE, en su última edición, recoge el vocablo «lama» en su actual acepción castellana, haciendo especial alusión al material geológico y limoso que suele estar presente en las áreas encharcadizas y humedales. Se define el término como «cieno blando, suelto y pegajoso, de color oscuro, que se halla en algunos lugares del fondo del mar o de los ríos, y en el de los recipientes o lugares en donde hay o ha habido agua largo tiempo». 
bonificación abordada en la Bética por la propia civilización romana. Son los casos de la bonificación de la Laguna Seca de Puerto Real (Cádiz) (Lagóstena Barrios, 2015) o las diversas acciones llevadas a cabo hace dos mil años en los humedales de la Campiña jiennense (Fornell Muñoz, 2015).

En la Edad Media, las extensas marismas del Guadalquivir, amplio humedal marítimo-terrestre heredado del «Lacus Ligustinus», se representaban de un modo peyorativo y sólo con posibilidades para la caza o la recolección. Manifestación de estas miradas negativas es el Libro de la Montería de Alfonso XI, el primer texto que recoge una descripción de las marismas béticas que, dado su despoblamiento, habrían de incorporarse a las tierras de realengo personal de la corona castellana, pues eran terrazgos muy aptos para la caza mayor y el ejercicio cinegético (Duque, 1977).

La Albufera valenciana también mantuvo esa vinculación histórica al mundo de la caza o la pesca, lo que propiciaría, mucho antes de su especialización arrocera, que, tras su reconquista, Jaime I la reservara para sí y su corona, aceptando, eso sí, que con anterioridad ya existía una importante actividad pesquera en la extensa laguna litoral (Sanmartín Arce, 1982).

El carácter negativo y, en ocasiones, despreciativo de los valores atribuidos a los humedales se pone de manifiesto incluso en el ideario subyacente que ha servido de soporte al léxico y la toponimia vernácula. Así lo testimonia F. González Bernáldez en un trabajo publicado en 1988. En él se acude al estudio de la terminología vernácula asignados a los humedales para explorar la percepción de sus valores.

Recoge el examen de 230 términos que aluden a los humedales o parte de éstos, y el resultado demuestra que esas denominaciones toponímicas gravitan alrededor de nueve conceptualizaciones de su imaginario colectivo (González Bernáldez et al, 1988). Junto a las ideas que sustentan una toponimia vinculada a la presencia del agua, lo salino, «el mar», los «ojos» o la existencia de suelos blandos y «trabados», destaca la terminología popular con connotaciones negativas frente a los humedales.

Incluso son muy conocidos los proverbios que aluden a esa negatividad. Recuérdese, por ejemplo, aquél que dice: «Agua corriente no mata a la gente, agua pará la puede matar» (íbidem: 580). Del mismo modo es usual la percepción negativa en los segundos significados que a veces poseen o son atribuidos a los humedales o sus componentes. Son ejemplo de esto último la aceptación «moral» de la palabra fango; en el significado de «suciedad, basura o excremento» que aparecen en ciertas representaciones de los humedales; y en el empleo figurado términos que relacionan las aguas paradas o estancadas como sinónimo de «atraso cultural», «estancamiento económico», etc.

La conjunción de las circunstancias referidas y esa «elosfobia» que, a nuestro entender, parece más que evidente a lo largo de la historia y se acentúa a 
partir de la Revolución Industrial (Arias García y Gómez Zotano, 2015), ha motivado que las diferentes comunidades humanas hayan esgrimido posturas de indiferencia, cuanto menos, ante los valores intrínsecos de los espacios húmedos, si bien, cuando han existido medios técnicos o económicos propicios, no han faltado las acciones que han motivado la práctica desaparición de un importante patrimonio natural, en ocasiones al amparo de normas y disposiciones legales que han facilitado y promovido tales prácticas. Sin olvidar que con frecuencia tales disposiciones legales han terminado por establecer una recalcitrante impronta social en la consideración negativa de tales superficies, que pervive incluso en el momento actual y que sigue amenazando la supervivencia de muchos humedales, sobre todo de aquellos que no poseen una declaración de protección específica.

\section{DESECACIÓN Y SANEAMIENTO DE MARISMAS Y HUMEDALES: LA «LEY CAMBÓ» Y La Ley de Desecación y Saneamiento de 1918}

Al igual que en otras regiones del Mediterráneo, pobladas desde antiguo e inmersas en esa aludida consideración «elosfóbica», la Revolución Industrial y el consecuente éxodo rural, serán algunos de los catalizadores que motiven una desconexión entre la población y los humedales, pues éstos acentúan sus caracteres negativos ante los nuevos modelos de producción y desarrollo, superando siglos de economía de subsistencia que había encontrado en las marismas, lagunas y pantanos un medio propicio para las prácticas cinegéticas o la recolección de diversos recursos. En este nuevo escenario, con el desarrollo tecnológico, la mecanización del campo, la necesidad de incrementar la superficie cultivable y la consideración de las zonas húmedas como espacios insalubres, se inicia un proceso de saneamiento y desecación de los humedales españoles en general y andaluces en particular (Montes, 1997; Arias García y Gómez Zotano, 2015).

A partir del siglo XIX, a la agricultura intensiva y mecanizada que exigía la modificación de los humedales endorreicos, se sumó, entrado el siglo xx, el ferviente proceso urbanizador del litoral que hizo lo propio con los humedales costeros (Barragán y Borja, 2010; Chica y Barragán, 2011); teniendo muy presente que tales acciones, más allá de proyectos locales y particulares, llegaron a contar con un significativo respaldo legal. Primero con las pioneras normas sobre el agua de 1866 y 1879, y más tarde con las «leyes Cambó» de 1918, que, entre otras consecuencias, impulsaron una evidente privatización de los recursos ecológicos que encerraban tales espacios.

Las disposiciones o proyectos que preveían la desecación de humedales en España son una constante, siempre en un marco ideológico en el que se favorecía la transformación del medio natural en nuevos territorios productivos y organizados. Sólo a título ilustrativo podemos citar aquí el proyecto de 1866 
para la desecación del Lago de Almonte (Huelva), junto a otras iniciativas de colonización que se harán recurrentes hasta prácticamente 1910 (Ojeda Rivera y Díaz del Olmo, 1987).

El documento de 1866 reflejaba las tesis que justificaban tal acción y esa histórica «elosfobia», pues en sus prolegómenos afirmaba: es un hecho demostrado por la experiencia de los siglos que todo terreno pantanoso es perjudicial para la salud (...) haciéndose extender su perniciosa influencia no solamente a los habitantes de la comarca que arrastran una vida miserable, sucumbiendo algunos de un modo casi fulminante bajo el influjo de las llamadas fiebres pútridas ${ }^{2}$.

Pero, aunque quizás cabría indagar y recoger aquí la existencia de disposiciones y propuestas anteriores ${ }^{3}$, no cabe duda de que serán las promulgadas a principios del siglo $\mathrm{xx}$, las que, por razones de oportunidad histórica y coyuntura socioeconómica, mayor efecto han generado en la casi total erradicación geográfica y ecológica de los antiguos humedales españoles. Y las que, por otra parte, más rastro han dejado en el ideario del colectivo nacional respecto a la «necesidad» de erradicar los indómitos humedales litorales e interiores, expresando y amparando esa antigua «elosfobia».

Si tales enclaves eran «sinónimo de pobreza, enfermedad y peligro», no había duda de que debían ser exterminados para facilitar su colonización agraria, erradicar sus insalubres condiciones o los focos de malas hierbas y alimañas que comprometían los campos de cultivos o los ganados que pastaban en sus inmediaciones. Eran, según el convencimiento del momento, una rémora al desarrollo; unos medios naturales (quizás los últimos), que estaban esperando a ser domados mediante el drenaje, la bonificación, la destrucción de sus riberas o la caza indiscriminada de su fauna. Unas acciones que, generalmente, habían de concluir con la aparición de nuevos campos de cultivo, la revalorización de sus suelos como espacios agrarios o incluso la transformación de antiguos humedales en jóvenes expansiones urbanas o rururbanas.

Esas normas son dos leyes gemelas por su simultaneidad cronológica, ambas publicadas el 24 de julio de 1918 y promovidas por Francisco Cambó, por entonces ministro de Fomento: la conocida como «Ley Cambó» de Paseos Marítimos de Barcelona, y la Ley de Desecación y Saneamiento de Marismas.

2. Citado en el artículo «La marisma domesticada. Doñana», publicado en Información Ambiental. Boletín REDIAM, el 8 de enero 2014, «on-line» en https://comunidadrediam.wordpress. com/2014/01/08/la-marisma-domesticada-donana/ [consultado en octubre de 2015].

3. Los ejemplos de proyectos e iniciativas en materia de desecación de lagunas, salinas y otros humedales en el territorio español son numerosos. Cabría citar a este respecto y en diferentes cronologías, los proyectos de desecación de la Laguna de Salinas (Alicante) (Arroyo Ilera, 1976), de la Laguna de Antela (Orense) (Fernández Soto et al., 2010), de la Laguna de la Nava (Palencia) (Alario Trigueros, 1989) o la desecación de los humedales del poniente de la provincia de Albacete (López Bermúdez, 1978). 
La primera de ellas establecía que los terrenos ganados al mar, así como los de la zona marítimo-terrestre, comprendidos dentro del proyecto que se apruebe, se cederán al Ayuntamiento de Barcelona como bienes patrimoniales, pudiendo ser enajenados una vez concluido el paseo marítimo realizado a expensas del ayuntamiento. Esta norma, con indudable repercusión sobre las condiciones naturales costeras, habrá de modelar buena parte de la fachada urbana de la Ciudad Condal y sus aledaños, pues establecía el procedimiento de ejecución del paseo marítimo entre el Llobregat y el Besós.

La otra ley coetánea se dictaba para favorecer el saneamiento y desecación de marismas y humedales. Se construía sobre la consideración de estas zonas como baldíos de infección palúdica; y tenía por objeto esencial variar su naturaleza hostil e inútil a través de la desecación, atribuyendo la propiedad de las nuevas áreas desecadas a los propietarios que acometieran el exterminio del humedal, lo que representaba una más que notable revaloración de las tierras que pudieran verse afectadas por tales proyectos.

A pesar de los claros matices antiecológicos de tales disposiciones, ambas leyes sólo han perdido su vigencia a partir de la Ley de Aguas de 1985 y la de Costas de 1988. Por otra parte, a pesar de haber sido derogadas, las disposiciones transitorias, en virtud de las diversas tipologías concesionarias y de acuerdo con la interpretación jurisprudencial, cabe la posibilidad de que subsistan propiedades de carácter privado, o concesiones de los humedales desecados y transformados en propiedad privada del concesionario como consecuencia de la transformación física del terreno. A lo que se suma la existencia de concesiones a perpetuidad por interés público.

Dicho de otro modo, la prolongada vigencia de lo dispuesto por ambas normas ha favorecido la perdurabilidad de sus efectos, la asimilación social colectiva de unos humedales exterminables por perjudiciales e inútiles, así como la pervivencia de una inercia legal y concesionaria que, por otra parte, suele contravenir las más modernas disposiciones legales en materia de conservación o las recomendaciones que a este respecto esgrimen diversos acuerdos internacionales sobre los humedales, los espacios naturales, el medio ambiente o la protección de los paisajes singulares.

\section{LOS AFANES DESECADORES EN LOS HUMEDALES DEL MEDIO GUADALQUIVIR}

Las consideraciones anteriores forman parte del bagaje geográfico de un proyecto más amplio en el que se aborda el estudio de los humedales andaluces en un territorio concreto, el que hemos denominado como «tramo medio del Guadalquivir» y que hemos concretado en el interfluvio existente entre dos afluentes del margen izquierdo del gran río de Andalucía: los ríos Genil y Guadalbullón. 
Dentro de este espacio, nuestro estudio general de los humedales continentales de Andalucía abarca un total de 89 términos municipales, pertenecientes a cuatro provincias, teniendo inventariados hasta la fecha un total de 141 humedales, a los que se deben añadir un buen número de salinas, de las que hemos censado un total de 66 unidades. El detalle del número de humedales por municipios y comarcas de que forman parte lo hemos expresado ya en una aportación anterior (Naranjo, Vega, 2015), encontrándose dentro de este conjunto de humedales ejemplos que disfrutan de un marchamo de calidad y excelencia ambiental que rozan la excepcionalidad, tales como las llamadas «Zonas Húmedas del Sur de Córdoba», algunas de las cuales disfrutan de la protección especialísima que les otorga su reconocimiento oficial como «Reservas Naturales».

Un resultado tan contundente en cuanto a número de humedales y a extensión superficial nos obliga, sin embargo, a elegir una muestra significativa que nos permita analizar y explicar con datos y referencias concretas estas actitudes que hemos denominado como «lamafobia»o «elosfobia». En este sentido, una muestra representativa y a la par homogénea pudiera ser la que se engloba dentro del espacio natural protegido de las mencionadas lagunas y humedales del sur de Córdoba, en el convencimiento de que cuanto digamos de estas zonas húmedas es válido y aplicable al conjunto general del espacio comprendido en la zona de la Depresión del Guadalquivir en su tramo medio.

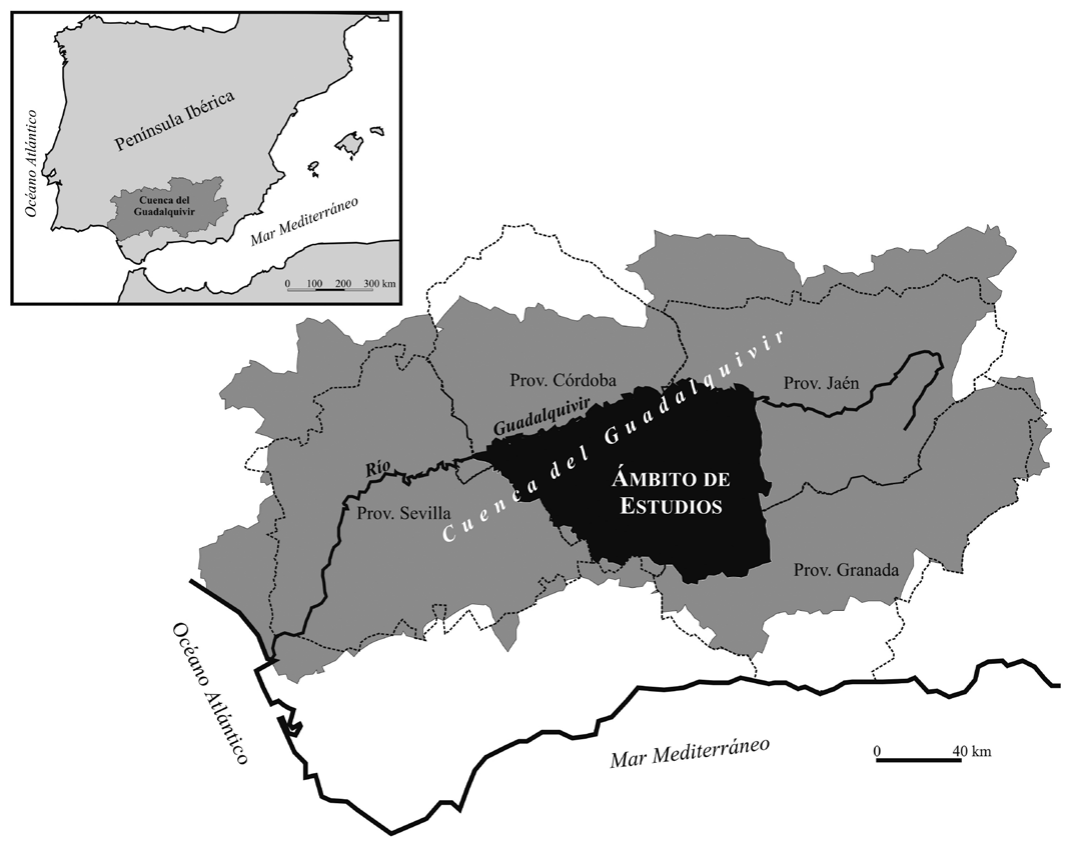

Figura 1: mapa de localización del ámbito de estudio. Elaboración propia. 
Todo ello porque estos humedales suponen un «paradigma de la evolución que en España ha tenido la consideración y tratamiento de nuestras zonas lacustres; y no sólo por sus valores naturales intrínsecos, estudiados con un nivel de exhaustividad más que aceptable, sino porque una mirada global (pasada y presente) sobre el conjunto de los espacios lagunares de esta zona nos muestra el panorama de un espacio que ha vivido y experimentado de una manera especialmente densa todas las problemáticas de la historia general y de la de este tipo de parajes en particular» (Naranjo, 2009).

\section{Presentación e identificación de los humedales principales}

Prescindiendo conscientemente (razones de espacio editorial nos obligan) del análisis del espacio geográfico en que se ubican estas lagunas (zona altocampiñesa de las provincias de Córdoba y Jaén, con algunos ejemplos en las provincias de Granada y Sevilla (Naranjo, 2014), procede indicar que nos enfrentamos a un auténtico rosario de humedales, zonas endorreicas de distinta entidad, tamaño y características, entre los que se encuentran una multitud de situaciones; desde elementos que, por su valor y singularidad han recibido la máxima consideración protectora dentro de la legislación ambiental andaluza (Reservas Naturales), a otras de menor entidad y significación.

Refiriéndonos en concreto a nuestra muestra de referencia, entre las lagunas del sur de Córdoba que ostentan el mayor grado de protección las hay de aguas permanentes («Zóñar», «Rincón» y «Amarga») y otras de aguas estacionales, tales como «Salobral», «Tíscar» y «Jarales»; y a estos elementos «mayores» se le añaden dos «parajes naturales» (humedales de origen antrópico) y todo un universo de lagunas y charcas de menor entidad, con aguas estacionales en todos los casos, en las que suele ser norma común la modesta superficie de su lámina de agua ${ }^{4}$. Considerando estos elementos menores del sistema, la posible excepcionalidad de este fenómeno queda diluida totalmente, pues la presencia de esas zonas endorreicas se extiende por multitud de términos municipales: en el caso de Córdoba: Aguilar de la Frontera, Lucena, Puente Genil, Baena, Cabra, La Carlota, Fuente Palmera, Montilla, Palma del Río, Priego de Córdoba, Santaella y Zuheros (Naranjo y Vega, 2015).

\section{Valores ambientales y paisajísticos}

Es cierto que muchas de estas pequeñas unidades lagunares no gozan de una protección legal específica, si bien son evidentes sus funciones y valores ecológico-ambientales, razón por la cual se les ha «arropado» con su inclusión en el

4. Entre ellas son dignas de mención las lagunas: Dulce, de Santiago, de La Quinta, Taraje, del Donadío, del Remendado, de Molina Ramírez, del Rincón del Muerto... y un largo etcétera. 
Inventario Nacional de Zonas Húmedas (Real Decreto 435/2004, BOE n. ${ }^{\circ} 73$, de 25/03/2004). A la par, la legislación andaluza los incluye en el «Inventario de Humedales de Andalucía» considerándolos como Humedales Andaluces (Decreto 98/2004, de 9 de marzo, BOJA número 66 de 05/04/2004).

Este número significativo de láminas de agua en la Andalucía interior supone, en primer lugar, la existencia de enclaves paisajísticos bien diferenciados de un entorno casi monopolísticamente agrario y con predominio neto del secano (Reques, 2005). La presencia de aguas, permanentes o estacionales, supone por otra parte la aparición de formaciones vegetales bien diferenciadas que, a su vez, dan cobijo a una fauna diversa y claramente distintiva respecto al resto del territorio.

Precisamente entre los muchos valores ambientales que adornan a estas lagunas, lo que de verdad e indudablemente les da sello de distinción es su variada avifauna, pues hablamos de un espacio que alberga especies como la Malvasía, el Ánade Real, Porrón Común, Pato Colorado, Focha Común, Porrón Moñudo, Pato Cuchara, Zampullín, Somormujo, Carriceros, Avetorillo, etc..., especies todas ellas que encuentran su lugar de cría e invernada en estos humedales (Alcalá-Zamora, 2014). Además las lagunas constituyen hábitats esenciales para la conservación de determinados grupos de especies (invertebrados acuáticos, anfibios, plantas acuáticas, etc.), algunos de ellos de carácter relicto (Reques, 2005).

Dentro de esta panorámica general sobresale con mucho la excelsa función que, en determinado momento, cumplieron algunos humedales para salvar del «peligro de extinción» en que se encontraba una especia concreta, el llamado «pato malvasía» (Oxyura leucocephala). El contingente de malvasías cabeciblancas había pasado de unos cien mil ejemplares a principios del siglo xx, distribuidos por toda Europa, a unos 50.000 individuos, que iban reduciendo progresivamente su presencia territorial a las zonas más cálidas. En el caso de España, a mediados del siglo xx el contingente se había reducido a unos 1.000 individuos y en 1970 apenas quedaban 100, a la par que prácticamente desaparecía de los países ribereños del Mediterráneo. Diversos conteos (en 1972, 1974, $1975 \ldots$...) constatan una alarmante reducción: en 1976 la población se limita a 30 ejemplares y en 1977 sólo se detectan 22 individuos, y todos están en estas lagunas, único lugar donde la malvasía se reproduce de forma continuada. (Torres, 2014).

En esta situación dramática se adoptaron medidas (no podemos entrar en el detalle de las mismas) que, en no mucho tiempo, revirtieron el estado de cosas, de manera que en el año 2000 el contingente de malvasías era ya de unos 4.500 individuos. Fue el momento más álgido; en años sucesivos descendió el número (2.175 ejemplares en 2013), lo que vino acompañado de la presencia de la 
malvasía cabeciblanca en otros muchos espacios de los que había desaparecido. Podía considerarse que el peligro de extinción estaba conjugado (Torres, 2014).

Pero todo esto ocurría - hay que hacerlo constar- a partir de los años setenta del siglo xx (1974), y precisamente el objeto de nuestro estudio se corresponde con el período anterior a esta etapa o, como mucho, con los momentos coetáneos a tales acontecimientos, período en que estos valores de los humedales ni si reconocían ni generaban espacios jurídicos de protección y, por consiguiente, quedaban al arbitrio de las decisiones de aquellos que ostentaban el derecho de propiedad sobre ellos.

\section{LOS INTENTOS DE DESECACIÓN DE LOS HUMEDALES ANDALUCES}

La administración pública (Junta de Andalucía, 2003) calcula que Andalucía ha perdido - principalmente por trabajos de desecación con fines agrícolas realizados en el siglo xx- la mitad de sus humedales, unos 120, y casi dos terceras partes de su superficie de zonas húmedas (aproximadamente 130.000 ha); entre ellos algunos espacios muy singulares, como la laguna de la Janda, o de tan importantes repercusiones ecológicas como las marismas del Guadalquivir en su margen izquierda (Zoido, 2002).

Todos los valores paisajísticos y ambientales mencionados de los humedales no fueron reconocidos hasta bien avanzada la segunda mitad del siglo xx. Hasta entonces, estas lagunas eran simples realidades naturales excepcionales en un entorno agrícola generalizado que se materializaba en un práctico monocultivo olivarero.

De hecho, cuando antes de estas fechas se mencionaban las lagunas se hacía, como mucho, para llamar la atención sobre esa excepcionalidad biológica, pero nada más. El mejor ejemplo es el del erudito decimonónico Juan de Dios Franco y Areco, que en un manuscrito inédito (1849-1856) escribe lo siguiente refiriéndose a las lagunas de «Zóñar» y «Rincón», en Aguilar de la Frontera:

A distancia de una media legua de la población, hay dos grandes lagos que fomentan la diversión de los aficionados a la caza y pesca de que abundan. El de Zóñar es muy nombrado en la historia por las clases de pájaros extraños que en él se crían: patos reales, mancones, zaramagullones, polluelas y otros aguátiles de hermosos y singulares colores; y no menos por las tencas, peces, crecidas anguilas y galápagos, con que sostiene en la mayor parte la Cartuja de Granada, en cuyo convento hay mucho consumo de esta última especie.

El lago del Rincón, aunque produce peces y nadan sobre sus aguas las mismas aves, no es con tanta abundancia. También contribuye el río con peces $y$ anguilas de muy buen gusto a la diversión y abastecimiento del vecindario. El campo es de los más divertidos de la comarca, y abundantísimo en caza de perdices, palomas tórtolas, codornices, liebres, conejos y, además, de zorzales y estorninos que vienen anualmente de tierras remotas a establecerse en los cañaverales que circundan el lago de Zóñar. 
Significa esto que en la visión que se tenía de los humedales prima una óptica pintoresca que, como es lógico, está supeditada en realidad a otros aspectos de la vida y sociedad de la época; concretamente supeditada a dos aspectos: la salud de la población y la producción agrícola. Y ambos aspectos, a veces por separado, a veces mezclados entre sí, van a actuar en el sentido de considerar estas lagunas como enemigos a combatir y eliminar; es decir, espacios susceptibles de una deseable la desecación.

\section{Desecación por razones higiénico-sanitarias}

Las razones de carácter higiénico-sanitario, aunque enmascarando frecuentemente otros argumentos de simple expansión agraria, han sido una constante justificativa para los intentos de desecación de muchos humedales.

El temor a las enfermedades ligadas a las aguas encharcadas supuso siempre un factor negativo en la percepción que de los humedales se tenía por parte de un sector importante de la población de estos lugares.

Y es que la malaria o paludismo (el «mal de las ciénagas»o «de los pantanos»), con bastante frecuencia hacía acto de presencia en estos espacios, actuando con virulencia y con resultados de una alta mortalidad. La estrecha relación entre lo que hoy llamamos humedales y el paludismo era una realidad incontestable, pues sabido es que la enfermedad se transmite por parásitos del género Plasmodium y por la picadura de mosquitos infectados del género Anopheles.

Y ante esta situación las actuaciones no fueron homogéneas, si bien la diferencia no estará tanto en el objetivo deseable (la desecación) como en la posibilidad y facilidad para conseguir ese objetivo.

Una referencia válida sobre estos comportamientos pudiera ser la laguna de «Zóñar», en el conjunto lagunar del sur de Córdoba, pues su carácter de aguas permanentes así como su considerable superficie (37 hectáreas) y profundidad (en torno a $16 \mathrm{~m}$.) hacían prácticamente imposible la desecación. Allí la lucha contra el paludismo se encauzó mediante la utilización de «armas» biológicas, y a ese objetivo respondió concretamente la introducción de ciertos elementos biológicos extraños al sistema, como fueron el pejerrey (Atherina boyeri) o la gambusia (Gambusia holbrooki), ictiofauna que, al alimentarse precisamente de las larvas y alevines del mosquito Anopheles, podría suponer un alivio importante en la difusión de la malaria.

Además de «Zóñar», éste es también el caso de la laguna «de Rincón», en la que desde 1886 se observan actuaciones en pro de la desecación, siguiendo entonces las directrices de una «Sociedad de Amigos del País» de Aguilar que proclamaba como justificación los efectos del paludismo en el poblado 


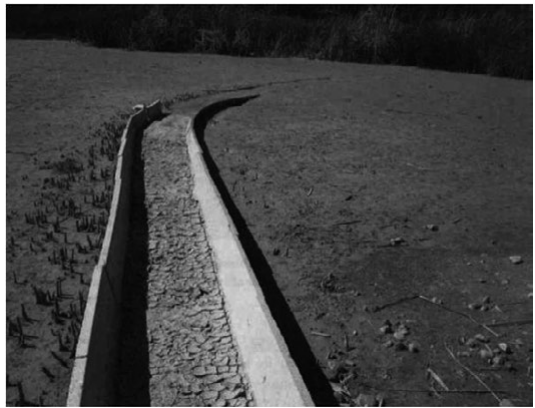

Figura 2: restos de la antigua conducción de aguas de «Zóñar» a Aguilar de la Frontera. Fuente: Junta de Andalucía.

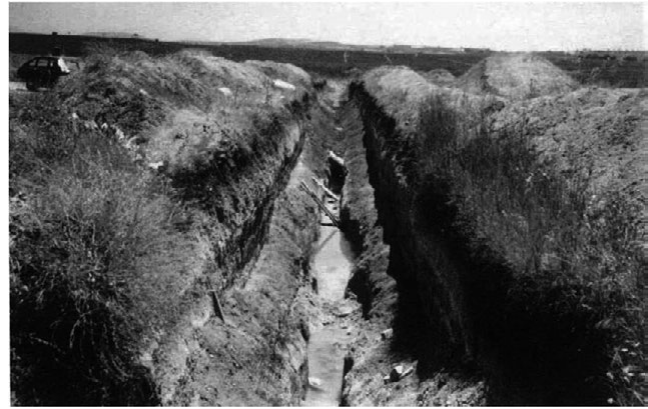

Figura 3: zanjas de desagüe efectuadas en la laguna «de Santiago», cerca de Moriles. Fuente: Junta de Andalucía.

de Zapateros (entonces término de Aguilar, germen poblacional del actual Moriles) $)^{5}$.

En 1904 el Ayuntamiento de Aguilar vuelve a recurrir al argumento higiénico-sanitario para, tras la declaración de la laguna como «Zona Insalubre», proceder a su desecación. El Ministerio de Obras Públicas encarga a D. Emiliano Serrano Navas la redacción del proyecto para «liquidar» la laguna. Se conserva este estudio (de 1907) en el archivo municipal de Aguilar de la Frontera, acompañado por tres planos a escala 1:2000, en los que se describe un estudio topográfico y parcelario de la laguna, así como el diseño del pozo y drenaje que habría de desecar su vaso ${ }^{6}$, si bien estos propósitos nunca llegaron a buen puerto, en buena medida por razones presupuestarias.

Los intentos de desecación de «Rincón» continuarán después, si bien estas otras actuaciones no aparecen ya tan claramente vinculadas a los argumentos higiénicos; volveremos sobre ello en el epígrafe siguiente.

\section{Desecación por razones de expansión del espacio agrario}

Los argumentos higiénico-sanitarios como fundamento de los intentos de desecación coexisten en la mayoría de los casos con un claro afán de ganar espacio agrario a costa de los humedales; y ello ocurre tanto en las grandes unidades del sistema como en otros elementos menores.

En la primera situación, la de los humedales de mayor significación y tamaño, vuelve a atraernos el ejemplo de «Zóñar», espacio híbrido en el que durante milenios coexistieron una realidad natural de índole acuática con la

5. Mención tomada de Torres (2004), que se basa en «las investigaciones de Carmelo Jiménez», aunque no cita su obra ni la procedencia de dichas investigaciones.

6. Plano general de la laguna del Rincón. Ingeniero Emilio Serrano Navas. Escala 1:2000. Archivo Municipal de Aguilar de la Frontera (Córdoba), Legajo 1.790. 
presencia de grupos humanos en los alrededores del humedal. Esta coexistencia se remonta al tercer milenio antes de Cristo, y parece evidente que de algún modo la interrelación entre humedal y colectivos humanos tuvo que ser una constante histórica.

Sin embargo, en lo que a nosotros nos ocupa, no se tiene constancia del afán desecador hasta el siglo XVI, momento en que se produce un desmonte en las zonas perilagunares, al tiempo que se instala una noria (la Noria Escobar) que se nutría de las aguas del manantial del mismo nombre y que, además de renovar con agua dulce la laguna, abastecía a determinadas huertas ubicadas en el mismo entorno. En parecido sentido se actuará en el último tercio del siglo xx, momento en que las actuaciones prodesecación se plasmaron en la captación de las aguas de los manantiales que vertían la laguna para el abastecimiento urbano de la población de Aguilar de la Frontera.

Por otra parte, en estos elementos lagunares de dimensiones importantes $\mathrm{y}$, por tanto, inasequibles para una desecación total, se constatan también otras actuaciones parciales como la intervención (ya en el siglo xx) en la orilla norte de «Zóñar» introduciendo elementos vegetales desecantes (eucaliptos), a la par que se intervenía más drásticamente en otras unidades menores del sistema conectadas con la laguna principal.

Nos referimos ahora a la laguna «del General», pequeño apéndice que, en años de pluviometría favorable, se rellenaba por rebosamiento de «Zóñar», y a la «laguna Chica o del Jarambel», conectada con Zóñar y con «el General» por el arroyo de la Humbrera.

En años lluviosos la subida del nivel de aguas permitía que las tres quedasen prácticamente unidas y comunicadas en una sola lámina de agua, en tanto que los años de pluviometría menos favorable, el afán desecador volvía a hacer acto de presencia. En este sentido, mediante la profundización artificial del cauce del arroyo en su salida por el oeste, la superficie de «el Jarambel» quedaba seca y en condiciones de ser sembrada. A este beneficio agrícola se unía que estas aguas rebosadas del complejo «Zóñar-General-Chica» acababa alimentando de aguas salobres unas salinas existentes antes de la desembocadura del Arroyo Humbrera en el río de Cabra.

«Zóñar» es, como ha podido comprobarse, fundamental, en nuestra exposición por cuanto, en su entorno, se ha podido observar toda la gama de actuaciones antrópicas imaginables en el sentido de la desecación (y en otros aspectos que aquí no abordamos). Pero Zóñar, por el tamaño de su vaso (unas 37 ha, con una cuenca de recepción de 876 ha) y por su profundidad, es una excepción, pues en todos los demás casos de lagunas en que la desecación se entendió viable, se actuó en esta dirección y con el mismo objetivo: incorporar a la superficie agraria el espacio lagunar (en todo lo que sigue, aprovechamos la experiencia de Torres Esquivias, 2004). 


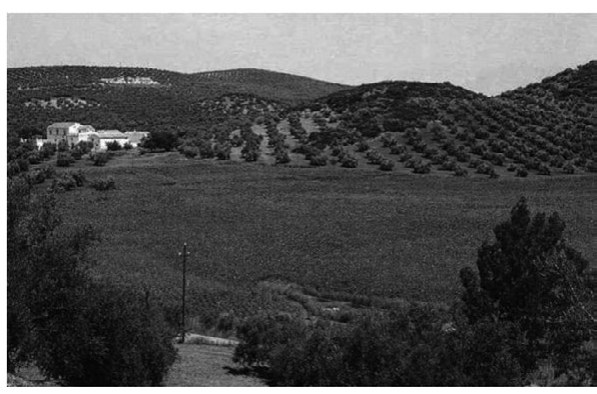

Figura 4: laguna Dulce (TM Lucena) cultivada en los años 80. Fuente: Junta de Andalucía.

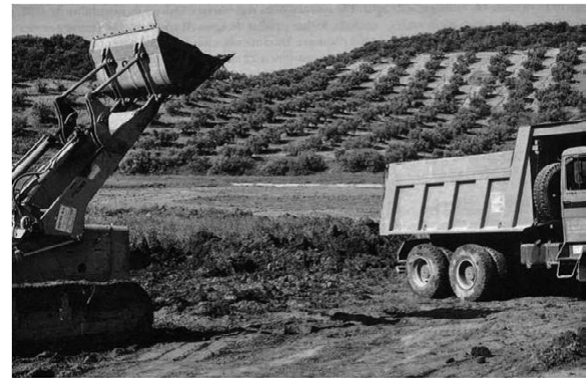

Figura 5: laguna Dulce durante los trabajos de restauración efectuados en los años 90 por la Administración Pública. Fuente: Junta de Andalucía.

Este es el caso de «Rincón», mencionado en el epígrafe anterior, donde a mediados del siglo $\mathrm{xx}$, tras un cambio en la propiedad, se vuelven a retomar otra vez los objetivos desecadores. Los nuevos titulares intentarán de manera pertinaz su desecación, aunque sin conseguirla nunca en su totalidad, pues la recuperación posterior de la lámina de agua era prácticamente automática. En 1972 se solicita y consigue subvención del Ministerio de Agricultura para financiar la desecación. A pesar de que la sequía actuó a su favor, nunca se consiguió el objetivo en su totalidad, lo que no es obstáculo para que, según las circunstancias, una parte mayor o menor del vaso fuesen sembradas y aprovechadas como espacios agrícolas.

Esta obsesión desecadora y otras circunstancias (actividad cinegética, presencia de bañistas, introducción de ictiofauna alóctona-carpas-, etc...) hicieron evidente el deterioro ambiental de esta laguna, lo que llevó a actuaciones que, descritas en otro lugar aunque inéditas cuando se redactan estas líneas ${ }^{7}$, llevaron a una intervención revolucionaria: la compra de la laguna por suscripción popular por parte de un colectivo ecologista («Amigos de la Malvasía») y la donación posterior de la misma a la Administración Autonómica, posición, desde la cual la pretendida eliminación de la laguna de «Rincón» se tradujo exactamente en lo contrario: la conformación de un enclave de especial fecundidad en lo que se refiere a la reproducción de las especies más delicadas y sensibles, entre ellas la «malvasía cabeciblanca».

7. Sobre este asunto tenemos dos trabajos pendientes de publicación; uno de ellos se inscribe en una colaboración con el proyecto de investigación dirigido por el Prof. F. Molinero Hernando, titulado «Paisajes patrimoniales de España», en el que hemos redactado un trabajo titulado: «Paisajes ecoculturales de los Humedales del Sur de Córdoba (España). Patrimonio y Patrimonialización ambiental en un contexto intensamente agrarizado»; y el otro se refiere a una propuesta de artículo presentado para su publicación en revista especializada y pendiente de aceptación cuando se escriben estas líneas, en el que analizamos el tema: «Los humedales del Sur de Córdoba. Paisaje agrario y patrimonio natural». 
En este contexto de una propiedad colectiva convertida después por donación en propiedad pública, la misma laguna fue escenario de una desecación peculiar y con finalidad de carácter ambiental y protectora. Esta actuación fue la respuesta al problema grave que suponía la presencia de una especie piscícola introducida por el hombre, la carpa, que estaba poniendo en grave peligro aquellos aspectos ambientales que servían de soporte a la presencia y reproducción de anátidas entre ellas la «malvasía».

Las escasas precipitaciones de 1985 y 1986 hicieron que, al final de este verano, el nivel de las aguas de «Rincón» fuese extremadamente bajo, lo que permitió actuar con una potente bomba hasta la desecación total. Exterminadas las carpas de aquel espacio lagunar, las lluvias otoñales permitieron la recuperación total de la laguna sin aquel pesado lastre y, de hecho, «Rincón» se convirtió en uno de los focos principales de reproducción de la malvasía.

Sí que resultó más eficaz el intento de desecación de otro elemento menor del sistema, la laguna «de Santiago», muy próxima a «Rincón» y en un nivel topográfico superior, en la que se estableció un sistema de drenaje artificial, una especie de rebosadero, que supuso la práctica pérdida del humedal durante bastante tiempo, ocupando su vaso con cultivos de cereal de secano.

Pero bastó la obturación (ni siquiera fue necesario un «sellado» completamente hermético) de ese rebosadero, para que la laguna de Santiago haya recuperado su carácter de humedal no permanente, visitado y utilizado por una avifauna muy atractiva; en concreto la presencia de los flamencos, favorecidos por su escasa profundidad, es bastante frecuente.

No faltó tampoco el intento de desecación de la laguna «Amarga», empeño para el que su propietario instaló un aliviadero en su extremo noroeste, útil cuando las aguas alcanzaban un nivel alto; como esto no ocurría siempre, dicho rebosadero fue ampliado mediante el uso de dinamita que, explosionada en esta grieta, ampliaba suficientemente el caudal de agua evacuada. Fueron distintos

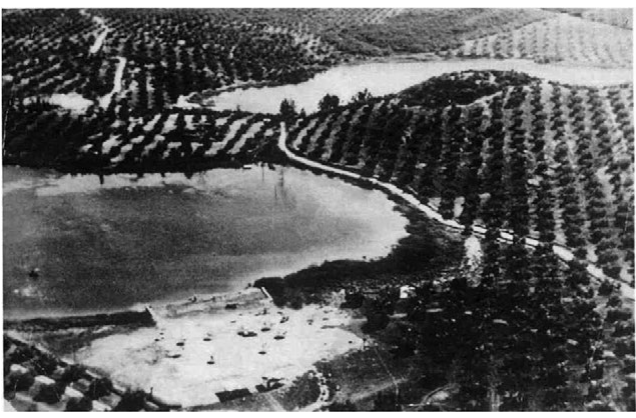

Figura 6: en la laguna Dulce se instaló en los años 60 del siglo xx una playa de interior. Al fondo, la laguna Amarga. Fuente: Junta de Andalucía. intentos sin que, al fin y a la postre, tales detonaciones cumplieran la finalidad perseguida.

Muy próxima a la laguna «Amarga», prácticamente contiguas, se encuentra la llamada laguna «Dulce», en la que los procesos de desecación se han visto favorecidos por las intensas deposiciones que, producto de una activísima erosión en las laderas circundantes, prácticamente han acabado por colmatar el vaso. No 
obstante también aquí estuvo presente el afán desecador, patente en la actuación que en 1978 supuso la excavación una profunda zanja, de aproximadamente $1.500 \mathrm{~m}$. de longitud, en la que se alojó una estructura de hormigón que recogía el agua de filtración y por gravedad la conducía al Arroyo Blanco, afluente del Genil. Esta acción antrópica eliminó el endorreísmo natural, propiciando la siembra de

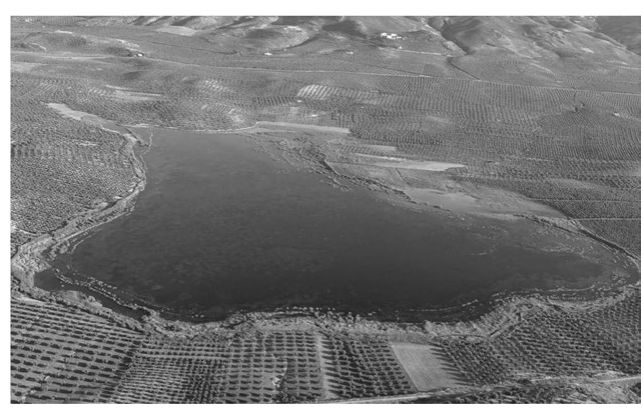

Figura 7: fotografía actual de la extensa laguna del Conde o del Salobral, en el TM de Luque.

Fuente: Juan de la Cruz Merino. este espacio con cereal y girasol hasta que, definitivamente, en 2011, el conducto de evacuación fue taponado por la administración ${ }^{8}$.

Pero el intento más pertinaz de desecación fue el de la laguna «del Conde o del Salobral», en Luque. Es el humedal de mayor superficie del sistema, aunque su carácter intermitente le hace perder teórico protagonismo respecto a otros elementos de aguas permanentes y de mayor profundidad, si bien no se puede ignorar que una laguna temporal y escasamente profunda como ésta, puede ser tan relevante o más desde el punto de vista de la biodiversidad como una laguna permanente.

Esta extensión y su escasa profundidad le hacían especialmente apetecible para convertir su lecho en tierras de cultivo; y de hecho, siendo estos terrenos de titularidad municipal, era habitual el arrendamiento para pastos, hasta el extremo de aparecer mencionado aquel entorno como la «Dehesa del Salobral». Precisamente en relación con los intentos desecadores, en 1829 «se instruye el correspondiente expediente y le es concedida la propiedad a censo enfitéutico»» al Conde de Luque; no debieron funcionarle bien las cosas al nuevo propietario porque «en noviembre de 1833 el Conde renuncia a su posesión, cosa que es aceptada por el cabildo, quedando nuevamente a su disposición». Y además de este primer intento, con otros protagonistas, existe constancia de tentativas de desecación en los años 1869, 1880, 1892, 1897, y 1902. (Arjona y Estrada, 1977).

Otros intentos desecadores o de disminución de la superficie inundada se constataron en «Tíscar» (donde se desvió parte del agua hacia el cauce del

8. No podemos dejar de mencionar una actividades pintoresca como la que en 1962 supuso la creación de una playa artificial en la orilla norte de esta laguna Dulce, playa de interior que funcionó durante unos años hasta que llegaron otros años de pluviometría escasa que obligaron al abandono de la actividad. 


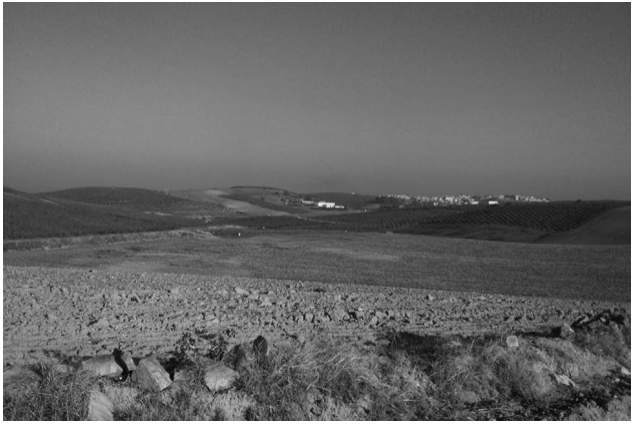

Figura 8: laguna del Basconcillo o de Villagallegos (TM Santaella). Ejemplo ilustrativo de la conversión de un humedal de campiña en espacio agrario. Fuente: Rafael F. Vega Pozuelo.

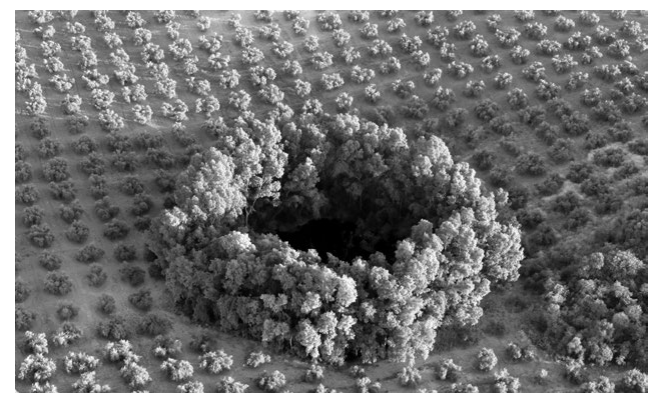

Figura 9: laguna del Butaquillo (Baena), literalmente sitiada por un cinturón perimetral desecante de eucaliptos. Fuente: Juan de la Cruz Merino.

Genil), y por supuesto en muchas de las unidades menores del sistema, donde se han dado la mano la intensa erosión en las laderas olivareras circundantes con la actuación directa y exprofeso del hombre para propiciar la conversión de muchos espacios acuáticos en campos de cultivo. En todo caso no deja de ser sorprendente la capacidad de resistencia del ecosistema ante agresiones muy poderosas; sobrecogen, en este sentido, imágenes como la de la Laguna del «Butaquillo», con sus riberas completamente sitiadas por una densa masa de eucaliptos que prácticamente están terminando ya con el humedal.

Entre tanto, se tiene constancia documental de la desecación de numerosos humedales de pequeña entidad, entre las lagunas «Dulce» (TM Lucena) y «de Santiago» (TM Aguilar de la Frontera), ya mencionadas, actualmente están restauradas por la Administración Pública y protegidas de posibles nuevos intentos desecadores; los «llanos del Acebuchoso», laguna de «Vadohondo», laguna de «las Albinas», laguna «del Taraje» (TM Lucena), laguna de «Cortijo Viejo» (TM Baena), laguna de «la Plata» o «Grande», «charco Bermejo» (TM La Carlota), laguna de «Prado del Moral» (TM Jaén), laguna de «Naranjeros» (TM Martos) y un largo etcétera (Vega, 2002).

\section{Desecación por otras razones de origen antrópico}

Un caso de especial interés lo constituyen los embalses de «Cordobilla»y «Malpasillo», respectivamente en los términos de Puente Genil (Córdoba) y Jauja-Badolatosa (Córdoba y Sevilla), embalses que, con la finalidad de proporcionar agua para el riego y la producción de energía eléctrica, se construyeron sobre el cauce del río Genil. 
Su carácter de obra humana no ha impedido que estos dos embalses se convirtieran en dos elementos más de esta red de espacios acuáticos que venimos mencionando, acogiendo gran variedad de avifauna que justificó que, dentro de las Zonas Húmedas del Sur de Córdoba, se les distinguiera con la figura de protección de «Parajes Naturales».

En este contexto, su singularidad actual procede del hecho de que una expansión olivarera muy agresiva sobre las inclinadas laderas excavadas por el cauce del río, han puesto en marcha procesos de erosión de tal intensidad que, en la actualidad, ambos embalses se encuentran prácticamente aterrados, hasta el punto de poner en peligro sus dos funciones básicas originarias: acumulación de agua para riego y producción de energía eléctrica.

Curiosamente el aterramiento con la consecuente pérdida de profundidad de sus aguas ha propiciado que en los lodos acumulados crezcan masas de vegetación que están sirviendo de hábitat a muchas especies; y más concretamente, las aguas someras y la escasa profundidad de sus fondos se han convertido en un atractivo para una avifauna (flamencos) que no era común en estos espacios.

\section{CONCLUSIONES}

En espacios que hoy son considerados «excelsos» por su calidad ambiental y fundamentales en lo que se refiere a su contribución a la conservación de determinados ecosistemas acuáticos de interior, la mentalidad que hemos denominado «lamafobia» o «elosfobia» no sólo ha estado presente, sino que ha sido un componente fundamental y básico que ha inspirado las relaciones del hombre con el medio hasta el último tercio del siglo xx.

En este sentido, una zona geográfica que ostenta (con perfecto derecho) el galardón y el honor de haber servido de escenario que permitió sacar una especie animal, la malvasía cabeciblanca, del riesgo grave de extinción, ha vivido previamente unas largas etapas de ignorancia e incomprensión de esos valores ambientales, hasta el extremo de ser una constante reiterada los intentos de eliminación de estos espacios acuáticos.

El saldo de este conjunto de fuerzas contrapuestas (desecación/protección) nos ha dejado, en lo positivo, la conservación de un conjunto de espacios naturales de probada excelencia por su calidad ambiental y paisajística. En lo negativo, muchos son los pequeños humedales que han desaparecido o están a punto de perderse.

En la actualidad, la desaparición de estos sistemas no es el único problema que hemos evidenciado en nuestro estudio. Se pueden detectar otras consecuencias de esa «lamafobia»o «elosfobia» que perduran, tales como la disminución o desaparición de la riqueza biológica y ecosistémica, la transformación y/o degradación del paisaje, etc. 


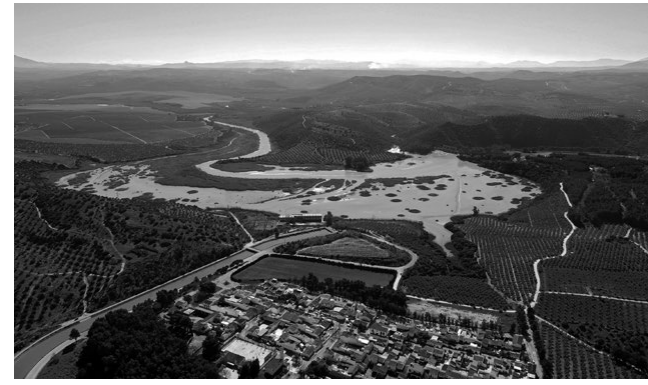

Figura 10: estado actual del paraje natural «Embalse de Cordobilla», prácticamente colmatado por una actividad erosiva de gran intensidad. Fuente: Juan de la Cruz Merino.
En este sentido son situaciones que, en mayor o menor medida, afectan a todos los humedales del medio Guadalquivir: procesos de eutrofización por contaminación química del agua, introducción de especies alóctonas que pueden llegar a ser invasoras, alteraciones hidrológicas, colmatación por acumulación de sedimentos y relleno de los vasos, presión urbanística $\mathrm{y}$ de infraestructuras, etc... Todos estos peligros se ciernen sobre ellos, lo que nos obliga a profundizar en el mejor conocimiento del estado actual de los humedales andaluces de interior como vía para conservarlos.

\section{BIBLIOGRAFÍA}

Alario Trigueros. M. (1989): «La desecación de la Nava: historia de una ambición», en Tabanque, n. ${ }^{\circ}$ 5, Dic. 1989, pp. 83-90.

AlcalÁ-Zamora Barrón, A. (2014)»Aves acuáticas de los humedales del sur de Córdoba», en Humedales cordobeses. 30 años de protección, pp. 53-60.

Arias García, J y Gómez Zotano, J. (2015): «La planificación y gestión de los humedales de Andalucía en el marco del convenio Ramsar», en Investigaciones Geográficas, n. ${ }^{\circ}$ 63, pp. 117-129.

Arroyo Ilera, R. (1976). «La laguna de Salinas (Alicante) y su desecación», en. Cuadernos de Geografía, n. ${ }^{\circ}, 18$, pp. 37-48.

Barragán, J. M. y BorJa, F. (2010): Evaluación de los ecosistemas del Milenio en España. Madrid: Ministerio de Medio Ambiente, Medio Rural y Marino, pp. 673-739.

Casermeiro Martínez, M. A. et al, (2002): Estado de los humedales españoles. Puesta en práctica de las recomendaciones Ramsar sobre su conservación y uso racional. Reflexiones de gestores y propuestas de WWF/Adena. Madrid: WWF/Adena, Artes Gráficas Palermo, S. L.

CAstro Lejarriaga, L. M. (2009): «Crecimiento económico y medioambiente», en Economía y Medio Ambiente, n. ${ }^{\circ}$ 847, Marzo-Abril'2009, pp. 93-110.

Corbin, A. (1988): Le territoire du vie. L'occident et le désir du rivage. París: Aubier. Traducción al castellano en A. Corbin (1993): Territorio del vacio. Barcelona: Edit. Mondadori.

Chica, J. A. y Barragán, J. M. (2011): Estado y tendencia de los servicios de los ecosistemas litorales de Andalucía. Sevilla: Consejería de Medio Ambiente.

De la Cruz, J. (coord.) (2014): Humedales cordobeses. 30 años de protección. Córdoba, Consejería Medio Ambiente y Ordenación del Territorio. Junta de Andalucía. 
DuQue, A. (1977): El mito de Doñana. Madrid: Servicio de Publicaciones del Ministerio de Educación.

DíEz Nicolás, J. (2004): El dilema de la supervivencia. Los españoles ante el Medio Ambiente. Madrid: Obra Social Caja Madrid.

Fernández Soto, M; Fernández García, A; Fernández Cuesta, G. y Fernández Prieto, J. R. (2019): «La desecación de la Laguna de Antela», en Boletín de la Asociación de Geógrafos Españoles, n. ${ }^{\circ}$ 57, pp. 295-312.

Fornell MuÑoz, A. (2015): «Aproximación al uso de los humedales de la Campiña jiennense en época romana», en L. G. Lagóstena Barrios: "Qui lacus aquae stagna paludes sunt...» Estudios históricos sobre humedales en la Bética. Cádiz: Seminario Agustín de Horozco de Estudios Económicos de Historia Antigua y Medieval, pp. 91-120.

Franco y Areco, J. de D. (1849-1856): Museo genealógico. Memorias de Aguilar (manuscrito inédito).

GonzÁlez Bernáldez, F; Rey, J. M. a y Ruiz, J. P. (1988): «Terminología vernácula y percepción ambiental de los humedales (wetlands)», en Homenaje a Pedro Montserrat, Zaragoza: Instituto de Estudios Altoaragoneses y el Instituto Pirenaico de Ecología (CSIC), pp. 579-582.

Have, Henk A. M. J. ten (Edit.) (2010): Ética ambiental y políticas internacionales. París: Organización de las Naciones Unidas para la Educación, la Ciencia y la Cultura.

Inglehart, R. (1977): The Silent Revolution. Princeton: Princeton University Press.

IngLeHART, R. (1990): Culture Shift in Advanced Industrial Society. Princeton: Princeton University Press.

Junta de Andalucía (2003): Plan Andaluz de Humedales. Sevilla.

LAGóstena BARrios, L. G. (Edit.) (2015): «Qui lacus aquae stagna paludes sunt...» Estudios históricos sobre humedales en la Bética. Cádiz: Seminario Agustín de Horozco de Estudios Económicos de Historia Antigua y Medieval.

Lagóstena Barrios, L. G. (Edit.) (2015): «Laguna Seca (Puerto Real, Cádiz) ¿Un caso de bonificación de tierras en Baetica?», en L. G. Lagóstena Barrios: «Qui lacus aquae stagna paludes sunt...» Estudios históricos sobre humedales en la Bética. Cádiz: Seminario Agustín de Horozco de Estudios Económicos de Historia Antigua y Medieval, pp. 61-90.

LÓPEZ Bermúdez, F. (1978): «El sector pantanoso al W de Albacete y su desecación», en Al-Basit, n. ${ }^{\circ} 4$, pp. 69-90.

Meadows, D. H; Meadows, D. L; Randers, J. y Behrens, W. W. (1972). The Limits to Growth. New York: Signet Books.

Montes, C. (1997): «Los humedales españoles: un desafío para la conservación de paisajes del agua amenazados», en S. A. Soler (Coord.): Manual de gestión del Medio Ambiente. Barcelona: Ariel S.A. pp. 101-115.

Morin, E. (2005) 7. a ed.: El Paradigma Perdido. Ensayo de bioantropología. Barcelona: Editorial Kairós, S.A. Primera edición en castellano de 1974. 
NARANJo, J. (2009): «Los humedales del Sur de Córdoba: Un espacio para la síntesis en las relaciones hombre-naturaleza», en Oxyura, revista sobre las zonas húmedas, n. ${ }^{\circ} 12$, pp. 3-6.

NARANJo, J. (2014): «Contexto geográfico de los humedales del sur de Córdoba», en Humedales cordobeses: 30 años de protección, pp. 1-9

NARANJo, J. y Vega, R. (2015): «Inventario abierto (cartografía y estudio del paisaje) de los humedales temporales mediterráneos: Avance de resultados», en de la Riva, J., Ibarra, P., Montorio, R., Rodrigues, M. (Eds): Análisis espacial y representación geográfica: innovación y aplicación. Universidad de Zaragoza-AGE, pp. 1775-1783.

Ojeda Rivera, J. F. y Díaz del Olmo, F. (1987): «El Condado litoral onubense: a la búsqueda de un modelo de desarrollo interno», en Revista de Estudios Andaluces, n. ${ }^{\circ} 8$, pp. $165-184$.

Roger, A. (2007): Breve tratado del paisaje. Madrid: Editorial Biblioteca Nueva, S. L. SANMARTín ArCE, R. (1982): La Albufera y sus hombres. Madrid: Akal Editor.

Montes, C. (1997): «Los humedales españoles: un desafío para la conservación de paisajes del agua amenazados», en S. A. Soler (Coord.): Manual de gestión del Medio Ambiente. Barcelona: Ariel S.A. pp. 101-115.

Morin, E. (2005) 7. a ed.: El Paradigma Perdido. Ensayo de bioantropología. Barcelona: Editorial Kairós, S.A. Primera edición en castellano de 1974.

Reques, R. (2005): Conservación de la biodiversidad de los humedales de Andalucía. Consejería de Medio Ambiente, Junta de Andalucía. Sevilla.

Roger, A. (2007): Breve tratado del paisaje. Madrid: Editorial Biblioteca Nueva, S. L. SANMARTín ArCE, R. (1982): La Albufera y sus hombres. Madrid: Akal Editor.

TORRes Esquivias, J. A. (2014): «Biología y evolución de la malvasía cabeciblanca en las Zonas Húmedas del Sur de Córdoba», en Humedales cordobeses: 30 años de protección, pp. 71-75.

VEGA, R. (2002): Inventario abierto, cartografía y caracterización de los humedales de la cuenca media del Guadalquivir; primeros pasos para su conservación. Inédito.

Zoido, F.; Venegas, C. (coords.) (2002): Paisaje y ordenación del territorio, Sevilla, Consejería de Obras Públicas y Transportes y Fundación Duques de Soria. 